\title{
Synchronous conjunctival melanoma and lentigo maligna melanoma*
}

\author{
Beatrice Mussio Fornazier Volpini ${ }^{1}$ \\ Jorge Agi ${ }^{1}$ \\ Rute Facchini Lellis ${ }^{3}$
}

\author{
Marcus Maia ${ }^{1}$ \\ José Vital Filho ${ }^{2}$
}

DOI: http:/ /dx.doi.org/10.1590/abd1806-4841.20176015

\begin{abstract}
Lentigo maligna has an extensive and neoplastic character. It typically progresses slowly and may eventually develop into an invasive melanoma, which is called lentigo maligna melanoma. Ocular melanoma is the second most common type of melanoma. The uvea is the most common site of origin of ocular melanomas, while conjunctival melanoma accounts for about $1-5 \%$ of cases. In this article, we describe a rare case of synchronic conjunctival melanoma and lentigo maligna on the face.
\end{abstract}

Keywords: Melanoma; Nevi and melanomas; Hutchinson's melanotic freckle

\section{INTRODUCTION}

In 1892, Hutchinson described a form of melanoma in situ that affected sun-exposed areas in the elderly and named it "senile freckles". Later, Dubreuilh coined the term lentigo maligna (LM), and demonstrated the extensive and neoplastic nature of the lesion. It typically progresses slowly and may eventually develop into an invasive melanoma, which is called lentigo maligna melanoma. ${ }^{1}$ The peak incidence is between $65-80$ years. Risk factors include fairskinned individuals with intense photodamaged skin. ${ }^{1}$

Lentigo maligna clinically presents itself as a smooth pigmented macule of variable size and color. ${ }^{1}$ Dermoscopy plays a key role in the diagnosis of LM, revealing characteristics such as gray dots, gray globules, dark rhomboidal structures, and asymmetric pigmented follicular openings. ${ }^{2}$

Ocular melanoma is the second most common type of melanoma. The uvea is the most common site of origin of ocular melanomas, comprising more than $80 \%$ of cases, while conjunctival melanoma accounts for about $1-5 \%$ of cases. Although most ocular melanomas are primary, cutaneous melanoma metastases may also occur in the ocular region, which represent less than $5 \%$ of all metastases to the eye and orbits. ${ }^{3}$ Conjunctival melanomas originate from melanocytes located in the basal layers of the conjunctival epithelium. Unlike other mucous membranes of the bulbar conjunctiva is directly exposed to solar radiation.
According to Jovanovic et al., conjunctiva melanoma occurs almost exclusively in white people, and only less than $1 \%$ are African-American patients. The incidence of this type of melanoma increases with age and it appears more frequently in the fifth and sixth decades of life. ${ }^{3-5}$

Conjunctival melanoma typically presents as a raised pigmented lesion, although sometimes it may be amelanotic, surrounded by prominent blood vessels or areas of primary acquired melanosis (PAM). It can appear in any conjunctival region including the bulbar conjunctiva, the eyelid, the fornices, semilunar fold, and caruncles. In most cases, the lesion develops at the limbus. Complaints about the sudden appearance of a local pigmented lesion is common, while irritation and pain are rare events..$^{3-5}$

The mainstay treatment of conjunctival melanoma is tumor resection with wide surgical margin. In most cases, adjunct therapy is associated with cryotherapy. Some authors recommend the use of additional brachytherapy. Orbital exenteration is reserved for cases in very advanced stages. Local tumor recurrence has been reported in $60 \%$ of patients. Metastases occur most commonly to the preauricular and submandibular lymph nodes. Mortality rate in 10 years is between $23 \%$ and $30 \%{ }^{4,6}$

Received on 09.05.2016

Approved by the Advisory Board and accepted for publication on 22.08.2016

* Work performed at Irmandade da Santa Casa de Misericórdia de São Paulo - São Paulo (SP), Brazil.

Financial support: none.

Conflict of interest: none.

Dermatology Clinic in the Department of Medicine at Irmandade da Santa Casa de Misericórdia de São Paulo - São Paulo (SP), Brazil.

Department of Ophthalmology in Irmandade da Santa Casa de Misericórdia de São Paulo - São Paulo (SP), Brazil.

Division of Dermatopathology in the Anatomical Pathology Service at Irmandade da Santa Casa de Misericórdia de São Paulo - São Paulo (SP), Brazil.

C2017 by Anais Brasileiros de Dermatologia 


\section{CASE REPORT}

We report an 85-year-old male patient complaining of a pigmented lesion in the right malar region and an ulcerated lesion of about $5 \mathrm{~cm}$ on the back. The lesions had been present for 2 years. Dermoscopy of the malar lesion showed multiple shades ranging from brown to black and dark rhomboidal structures with asymmetric perifollicular pigmentation (Figure 1).

Physical examination revealed a brownish and unilateral pigment in the conjunctival lesion. The patient reported to be unaware of the existence of the lesion. Ophthalmologic evaluation showed an ocular melanoma. Therefore, we scheduled a biopsy of the lesion (Figures 2 and 3).

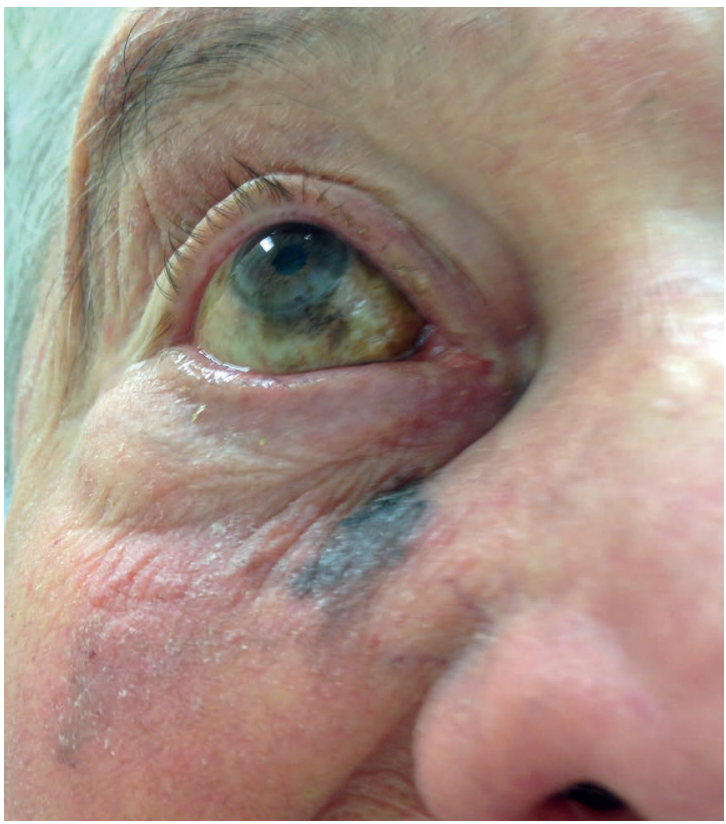

Figure 1: Conjunctival melanoma and lentigo maligna melanoma

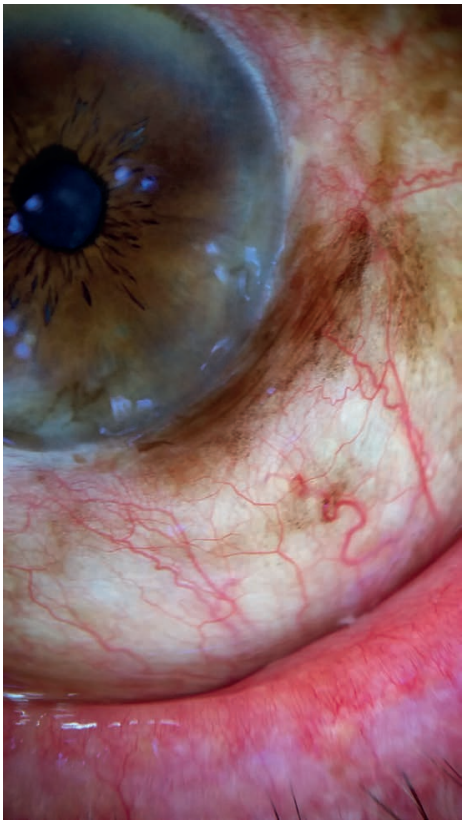

Figure 2:

Dermoscopy of the ocular lesion
The patient underwent excision of both lesions with the following histopathological diagnoses: lesion in the right malar region - lentigo maligna melanoma, Breslow $0.7 \mathrm{~mm}$, Clark III, mitotic index $=0 / \mathrm{mm}^{2}$, absence of ulceration, perineural invasion, undetected angiolymphatic invasion, discrete perineural infiltration of lymphocytes, absence of regression, no satellitosis, and free margins; lesion on the back - nodular basal cell carcinoma, ulceration, and undetected angiolymphatic invasion (Figure 4).

After a biopsy of the lesion, we diagnosed ocular melanoma in situ (Figure 5).

The indicated treatment for an ocular melanoma in situ is the surgical resection, but the patient refused treatment and failed to show for the scheduled appointments.

\section{DISCUSSION}

Conjunctival melanoma is a rare disease that may arise de novo or from pre-existing conditions such as PAM or conjunctival nevus. About $60 \%$ of melanomas arise from PAM. Studies show

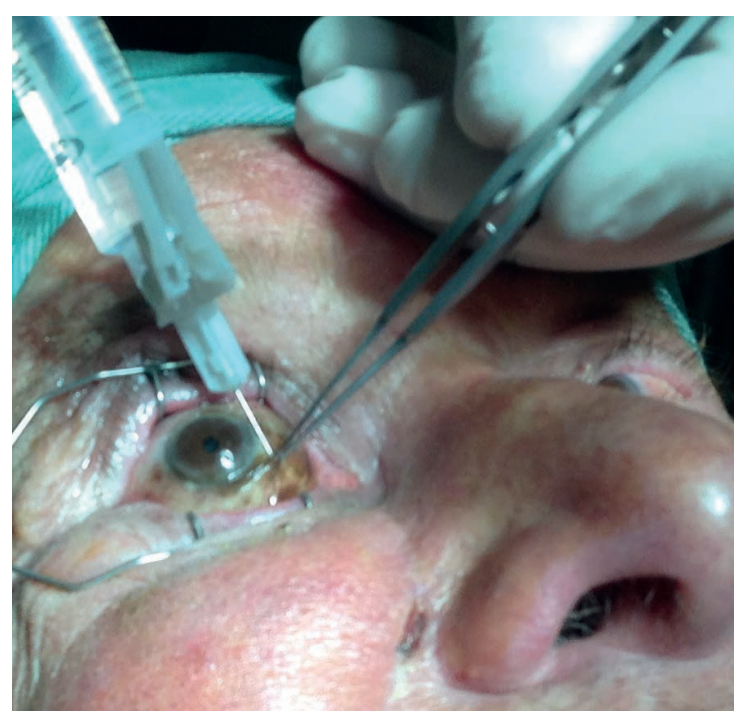

Figure 3: Ocular biopsy

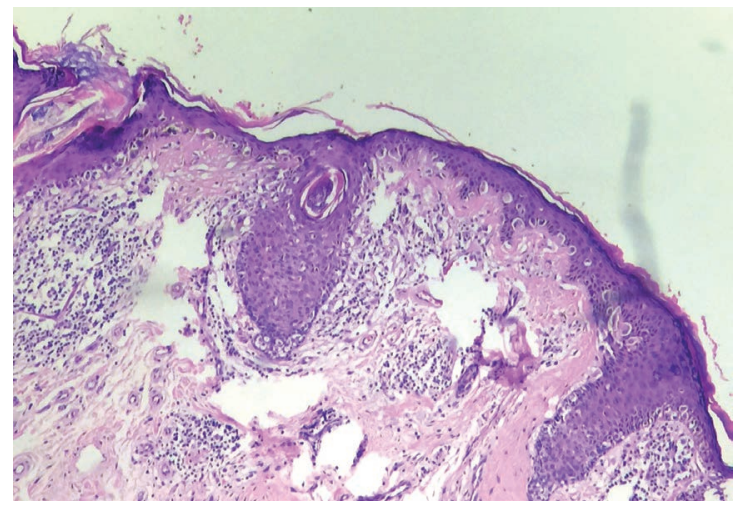

Figure 4: Continuous and atypical melanocytic-epidermal proliferation extending to the follicular infundibulum. The dermis presents intense basophilic degeneration of collagen (Hematoxylin \& eosin X100) 


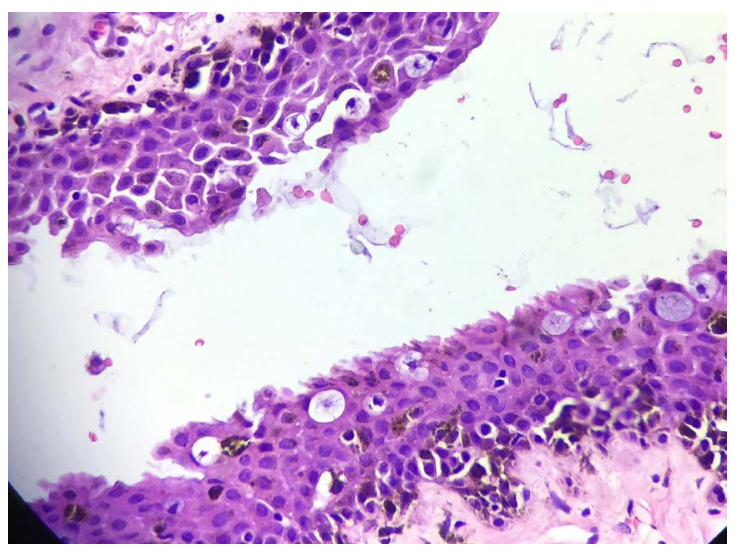

Figure 5: Atypical melanocytic proliferation in the conjunctival epithelium with the presence of Paget cells. (Hematoxylin \& eosin X400) similar pattern of increased incidence of cutaneous melanoma and conjunctival melanoma, suggesting a possible link to sunlight exposure and its role in the etiology of conjunctiva melanomas. ${ }^{3,4,7,8}$

The present case demonstrates the importance of dermoscopy for a precise clinical diagnosis and the importance of multidisciplinary work. $\square$

\section{REFERENCES}

1. Wainstein A, Belfort F. Melanoma - prevenção, diagnóstico, tratamento e acompanhamento 2. ed. São Paulo: Atheneu; 2014.

2. Schiffner R, Schiffner-Rohe J, Vogt T, Landthaler M, Wlotzke U, Cognetta AB, et al. Improvement of early recognition of lentigo maligna using dermatoscopy. J Am Acad Dermatol. 2000;42:25-32.

3. Jovanovic P, Mihajlovic M, Djordjevic-Jocic J, Vlajkovic S, Cekic S, Stefanovic V. Ocular melanoma: an overview of the current status. Int J Clin Exp Pathol. 2013:6:1230-44.

4. Salcedo-Hernández RA, Luna-Ortiz K, Lino-Silva LS, Herrera-Gómez A, Villavicencio-Valencia V, Tejeda-Rojas M , et al. Conjunctival melanoma: survival analysis in twenty-two Mexican patients Arq Bras Oftalmol. 2014;77:155-8.

5. Singh AD, Ventura A. Oncologia oftalmológica clínica. Rio de Janeiro: Guanabara Koogan; 2009.

6. Rodríguez-Martín M, Rodríguez-Martín J, de Paz NM, Ferrer PC, Cabrera PR, Rodríguez Martín B, et al. Conjunctival Melanoma: A New Clinical and Therapeutical Approach. Case Rep Dermatol. 2010;2:149-155.

7. Hicks C, Liu C, Hiranandani M, Garner A, Hungerford J. Conjunctival melanoma after excision of a lentigo maligna melanoma in the ipsilateral eyelid skin. $\mathrm{Br} \mathrm{J}$ Ophthalmol. 1994;78:317-8.

8. Giblin ME, Shields JA, Shields CL, Eagle RC Jr. Primary eyelid malignant melanoma associated with primary conjunctival malignant melanoma. Aust N Z J Ophthalmol. 1988;16:127-31.

\author{
MAILING ADDRESS: \\ Beatrice Mussio Fornazier Volpini \\ Rua Dr. Cesário Mota Júnior, 112 \\ Consolação \\ 01221-020 - São Paulo, SP \\ Brazil \\ E-mail: beatricevolpini@gmail.com
}

How to cite this article: Volpini BMF, Maia M, Agi J, Vital JF, Lellis RF. Synchronous conjunctival melanoma and lentigo maligna melanoma. An Bras Dermatol. 2017;92(4):565-7. 